\title{
Camurati-Engelmann disease
}

\section{S Pathmanathan 1 , Noel P Somasundaram², Anil de Silva ${ }^{3}$, J Jeyakumar ${ }^{4}$, M V Perera Anandi Samarasekara ${ }^{6}$}

Sri Lanka Journal of Diabetes Endocrinology and Metabolism 2011; 1: 54

A 59 year-old man presented with left sided lower motor neurone facial nerve palsy and reduced hearing of 5 years duration, and noted recent worsening of symptoms. He had lower limb deformities since childhood but denied recurrent fractures or family history of similar illness. He was initially presumed to have polyostotic Paget's disease on the basis of his age, the presentation and radiological appearance. However after careful evaluation, CamuratiEngelmann disease (CED) was diagnosed on the basis of radiological appearances and histological examination of bone. CED, also known as progressive diaphyseal dysplasia, is a rare genetic disorder of unknown etiology characterized by progressive expansion and sclerosis predominately affecting the diaphyses of long bones and associated with cranial sclerosis $(1,2,3)$.

Our patient had striking radiographic changes of skull and long bones. Plain Xray showed expansile sclerotic bone lesions of tubular bones, skull vault and mandible. The long bones showed a remarkably symmetrical involvement mainly of their diaphysis. On comparison, Paget's disease, shows an asymmetrical involvement of long bones and usually begins at the end of a bone. Pelvis is commonly involved in Paget's disease $(4,5)$. In our patient pelvis was relatively spared.

Histology of the left humerus showed mature thick cortical lamellar bone with regular prominent cement lines. Prominent osteoblasts were present on the surface of bone

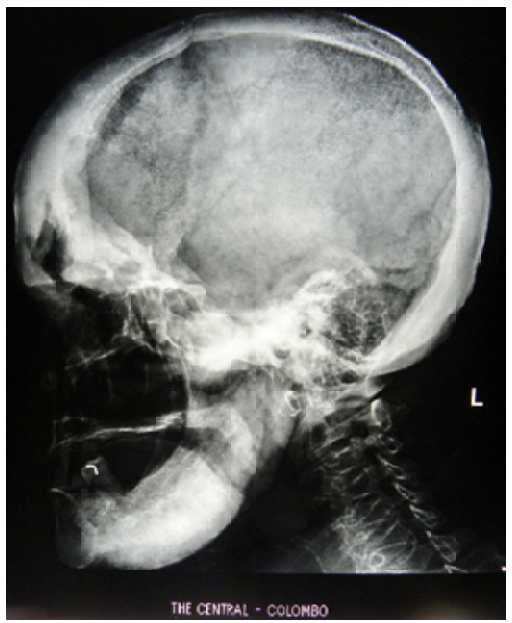

Figure 1. Xray skull - lateral. within the haversian canals. There was no osteoclastic activity or significant inflammation seen. In comparison, in the mature lesion of Paget's disease, there is a mixture of lamellar and woven bone, which transforms the matrix into a chaotic "mosaic" pattern of irregularly juxtaposed pieces of lamellar bone, interspersed with woven bone $(4,5)$. This was not observed in our patient.

\section{References}

1. Ramanan V, Hall MJ, Baildam EM, Mughal Z. CamuratiEngelmann disease - a case report and literature review. Rheumatology 2005; 44 (8): 1069-72.

2. Minford AM, Hardy GJ, Forsythe WI, Fitton JM, Rowe VL. Engelmann's disease and the effect of corticosteroids. A case report. The Journal of Bone and Joint Surgery 1981; 63B(4): 597-600.

3. Janssens K, Vanhoenacker F, Bonduelle M, Verbruggen L, Van Maldergem L, Ralston S, et al. Camurati-Engelmann disease: review of the clinical, radiological, and molecular data of 24 families and implications for diagnosis and treatment. J Med Genet 2006; 43:1-11.

4. Schneider D, Hofmann MT, Peterson JA. Diagnosis and Treatment of Paget's Disease of Bone. Am Fam Physician 2002; 65(10): 2069-73.

5. Frederick R. Singer, MD. Paget's Disease of Bone Chapter 15, www.endotext.org (Accessed date - 21st May 2011).

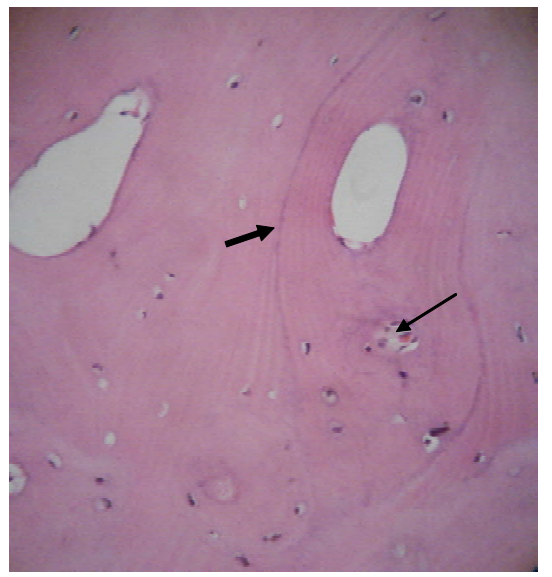

Figure 2. Histology of the bone biopsy shows mature thick cortical lamellar bone with regular prominent cement lines (thick arrow) with prominent osteoblasts (thin arrow) within the harvesian canal.

${ }^{1}$ Senior Registrar, Endocrinology, ${ }^{2}$ Consultant Endocrinologist, ${ }^{3}$ Consultant Radiologist, ${ }^{4}$ Senior Registrar, Orthopedic, ${ }^{5}$ Consultant Orthopedic Surgeon, ${ }^{6}$ Consultant Histo Pathologist, National Hospital of Sri Lanka. 